\title{
Corneal Endothelial Morphology in Children with Type 1 Diabetes
}

\author{
Mohamed Anbar, ${ }^{1}$ Hatem Ammar, ${ }^{1}$ and Ramadan A. Mahmoud ${ }^{2}$ \\ ${ }^{1}$ Department of Ophthalmology, Faculty of Medicine, Sohag University, Sohag 82524, Egypt \\ ${ }^{2}$ Department of Pediatrics, Faculty of Medicine, Sohag University, Sohag 82524, Egypt \\ Correspondence should be addressed to Ramadan A. Mahmoud; ramadan.aboelhassan@yahoo.com
}

Received 10 April 2016; Accepted 29 May 2016

Academic Editor: Marco Songini

Copyright (C) 2016 Mohamed Anbar et al. This is an open access article distributed under the Creative Commons Attribution License, which permits unrestricted use, distribution, and reproduction in any medium, provided the original work is properly cited.

\begin{abstract}
Aim. To investigate corneal endothelial cell morphological in children with type 1 diabetes and to determine the systemic and local factors that contribute to these changes. Methods. One hundred sixty eyes of 80 children with type 1 diabetes and 80 eyes of 40 normal children as a control during the period from July 2015 to February 2016 underwent full clinical and ophthalmologic examination. We measured the central corneal thickness (CCT), endothelial cell density (ECD), ploymegathism, and pleomorphism using a noncontact specular microscope. Results. The mean age of the diabetic children was $8.22 \pm 3.11$ years. The mean duration of type 1 diabetes was $3.51 \pm 2.23$ years. The mean CCT was significantly higher: $537 \pm 33.41$ microns (right eye), in the diabetic group compared to the control group. The mean ECD in patients with type 1 diabetes was $3149.84 \pm 343.75$ cells $/ \mathrm{mm}^{2}$ (right eye), and it was significantly lower than in the control group. Furthermore, pleomorphism was significantly lower $48.73 \pm 5.43 \%$ (right eye), in the diabetic group compared to the control group. The mean polymegathism was significantly higher $37.96 \pm 5.61 \%$ (right eye), in the diabetic group compared to the control group. All of these changes are significantly correlated only with the duration of diabetes. Conclusions. Diabetic children have thicker corneas, lower ECD, an increased polymegathism, and a decreased pleomorphism. The duration of diabetes is the factor that affects all of these changes. To what extent these changes affect visional function on long term needs to be investigated in further studies.
\end{abstract}

\section{Introduction}

Type 1 diabetes is a chronic illness characterized by the body's inability to produce insulin due to the autoimmune destruction of the beta cells in the pancreas. Onset most often occurs in childhood. Type 1 diabetes is the most common metabolic disease of childhood. About one in every 400-600 children and adolescents has type 1 diabetes. Its prevalence has increased over recent years. Diabetes mellitus is a systemic disease that alters the major metabolic pathway in the human body, affecting all organ systems [1-3].

Eye complications occur with long standing diabetes. Diabetic retinopathy is the most commonly investigated ocular complication [4]. However, morphologic and functional changes in the cornea have been studied less frequently in diabetic eyes. The corneal endothelium is a single layer of uniformly sized cells with a hexagonal shape. Their amount decreases by approximately $0.5 \%-0.6 \%(100-200$ cells $)$ per year [5]. The endothelial cell dysfunction is observed in myopia and in contact lens wearers [6,7].

When corneal endothelial function decreases, corneal hydration and, consequently, the central corneal thickness (CCT) increase [8]. Many studies have shown that even minor changes in the morphology of the endothelial cells may manifest in the disturbances in the tightness of the endothelial barrier $[5,8,9]$.

There are many reports concerning an analysis of the corneal endothelium in adults with type 1 and type 2 diabetes [10-13]. However, there are only some publications concerning an analysis of the cornea in type 1 diabetes in children $[14,15]$. Prevention of the corneal endothelium dysfunction, its early detection, and immediate treatment are thus crucial, particularly if the problem concerns young patients. Therefore, the aim of this prospective cross-sectional 
study was to measure the central corneal thickness (CCT), endothelial cell density (ECD), coefficient of variation of cell size (polymegathism), and corneal cell variation in shape as a percentage of hexagonal cells (pleomorphism) using a noncontact specular microscope and to evaluate the local and systemic factors that may affect the corneal endothelium in this group of patients.

\section{Materials and Methods}

The current study was performed at the Pediatrics Diabetic outpatients clinic in the Pediatrics Department in cooperation with the Department of Ophthalmology, Faculty of Medicine, Sohag University, during the period from July 2015 to February 2016. Ethical approval for the study and the investigation was obtained from the Research Committee of Medical Faculty at Sohag University, and written informed consent was obtained from all parents of the children.

For the purpose of this study we examined corneal endothelial morphology in 160 eyes of 80 children with type 1 diabetes. We also examined 80 eyes of 40 normal children as a control. Children who used contact lenses or had previous ocular trauma, prior ocular surgery, intraocular inflammation, or refractive errors or who were taking topical medication were excluded from the study.

A complete history was taken for all diabetic patients including age, gender, and diabetes duration; the general examination included body mass index (BMI) and other systemic examinations; laboratory data collection included hemoglobin level and last glycosylated hemoglobin (HbA1C) level. Data from both eyes of every diabetic patient and the control children were collected in this study-a complete ophthalmological examination including visual acuity, slit lamp examination, intraocular pressure measurements, and fundus examination with a binocular indirect ophthalmoscopy. The corneal endothelium morphology, including central corneal thickness (CCT), endothelial cell density (ECD), corneal cell variation in size as percentage of abnormal size (corneal polymegathism), and corneal cell variation in shape as a percentage of hexagonal cells (corneal pleomorphism), was analyzed using a noncontact specular microscope (Topcon SP-1P, Tokyo, Japan). Endothelial cell density (ECD) was performed by asking the patients to look to the fixation target, when the pupil is displayed; operator taped the area around the pupil; the photographing head moves to display the pupil image and the alignment dot on the center of the screen. Alignment starts automatically and photographing is performed. Multiple images were taken with panorama view and the best quality image was analyzed. The best image quality was obtained when all cell borders, boundaries, and centers across a single image of the endothelium are distinct excluding the peripheral edges of the image and had a sufficient number of cells to count at least 50 and as many as 150 cells contiguous to each other. In this study the centers of 100 adjacent cells were marked and analyzed by built-in image analysis software.

Therefore, the aim of this study was to compare the corneal endothelial cell morphology and the central corneal thickness in diabetic and normal children and to correlate the abnormalities - if found - to risk factors such as age, sex, BMI, hemoglobin level, duration of diabetes, or metabolic control.

2.1. Statistical Analysis. Data was analyzed using STATA intercooled version 12.1. Quantitative data was represented as mean and standard deviation. Data was analyzed using Student's $t$-test to compare the means of two groups. Qualitative data was presented as a number and percentage and compared using chi-square test. Multivariate regression analyses were done to determine different eye parameters. $P$ value was considered significant if it was less than 0.05 .

\section{Results}

In this study, there were no abnormalities found in ophthalmological examination including visual acuity, slit lamp examination, intraocular pressure measurements, and fundus examination in type 1 diabetes patients or control group. Furthermore, as shown in Table 1, the corneal endothelial morphology in 160 eyes of 80 children with type 1 diabetes (32 (40\%) boys and 48 (60\%) girls) was examined. The age of the diabetic children ranged from 2 to 14 years (mean: $8.22 \pm 3.11$ ). The duration of type 1 diabetes ranged from 0.5 to 8 years (mean: $3.51 \pm 2.23$ ), which was subdivided into $30(37.50 \%)$ children with a duration less than 2.5 years, 33 $(41.25 \%)$ children with a duration of 2.5 to 5 years, and 17 $(21.25 \%)$ children with a duration of more than 5 years. We also examined 80 eyes of 40 normal children as a control (14 (35\%) boys and 26 girls (65\%)); the age of the control group ranged from 3 to 13 years (mean: $7.83 \pm 2.48$ ).

As shown in Table 2, the range of $\mathrm{HbA1C}$ was $6.5 \%$ to $14.2 \%$ with a mean value of $8.33 \pm 2.3 \%$. There were $31(38.75 \%)$ children with poor metabolic control (HbA1C, $>8 \%), 27(33.75 \%)$ children with moderate metabolic control (HbAlC, 7-8\%), and $22(27.50 \%)$ children with good metabolic control ( $\mathrm{HbA} 1 \mathrm{C}<7 \%)$.

As shown in Table 3, a group of 80 children with type 1 diabetes was examined. The mean endothelial cell density (ECD) of the right eye in patients with diabetes was $3149.84 \pm$ 343.75 cells $/ \mathrm{mm}^{2}$, and it was significantly lower than that in the control group $\left(3308.78 \pm 99.33\right.$ cells $\left./ \mathrm{mm}^{2}\right)(P=0.005)$. The mean endothelial cell density (ECD) of the left eye in patients with diabetes was $3142.13 \pm 416.74$ cells $/ \mathrm{mm}^{2}$ and it was significantly lower than that in the control group $\left(3315.25 \pm 100.16\right.$ cells $\left./ \mathrm{mm}^{2}\right)(P=0.01)$. The mean CCT of the right eye was $537 \pm 33.41$ microns in the diabetic group versus $504.7 \pm 23.99$ microns in the control group $(P<$ $0.0001)$, while the mean CCT of the left eye was $539.91 \pm 30.49$ microns in the diabetic group versus $501.63 \pm 15.77$ microns in the control group $(P<0.0001)$.

As shown also in Table 3, the mean pleomorphism of the right eye was $48.73 \pm 5.43 \%$ in the diabetic group versus $56.46 \pm 9.64 \%$ in the control group $(P<0.0001)$, while the mean pleomorphism of the left eye was $49.67 \pm 6.87 \%$ in the diabetic group versus $55.14 \pm 10.27 \%$ in the control group $(P<0.003)$. Furthermore, the mean polymegathism of the right eye was $37.96 \pm 5.61 \%$ in the diabetic group versus 
TABLE 1: Criteria of studied populations.

\begin{tabular}{|c|c|c|c|}
\hline Patient characteristics & Type 1 diabetes & Healthy controls & $P$ value \\
\hline \multicolumn{4}{|l|}{ Age (years) } \\
\hline Mean (SD) & $8.22 \pm 3.11$ & $7.83 \pm 2.48$ & \multirow{2}{*}{0.48} \\
\hline Median (range) & $9(2-14)$ & $8(3-13)$ & \\
\hline \multicolumn{4}{|l|}{ Gender } \\
\hline Females (median and range) & $48(60.00 \%)$ & $26(65.00 \%)$ & \multirow{2}{*}{0.60} \\
\hline Males (median and range) & $32(40.00 \%)$ & $14(35.00 \%)$ & \\
\hline \multicolumn{4}{|l|}{ Weight $(\mathrm{kg})$} \\
\hline Mean (SD) & $28.34 \pm 9.73$ & $26.05 \pm 6.36$ & 0.18 \\
\hline \multicolumn{4}{|l|}{ BMI } \\
\hline Mean (SD) & $17.18 \pm 2.81$ & $17.61 \pm 1.57$ & 0.38 \\
\hline \multicolumn{4}{|l|}{ Hemoglobin (g/dL) } \\
\hline Mean (SD) & $12.37 \pm 1.04$ & $12.54 \pm 0.51$ & 0.35 \\
\hline \multicolumn{4}{|l|}{$\mathrm{HbAlC}$ in percentage } \\
\hline Mean (SD) & $8.33 \% \pm 2.31$ & $4.33 \% \pm 0.83$ & $<0.0001$ \\
\hline
\end{tabular}

BMI: body mass index; HbAlC: glycosylated hemoglobin.

TABLE 2: The duration of type $1 \mathrm{DM}$ in years and the degree of metabolic control represented by HbA1C percentage.

\begin{tabular}{lc}
\hline Patient characteristics & Summary statistics \\
\hline $\begin{array}{l}\text { Duration of type 1 DM/years } \\
\quad<2.5 \text { years }\end{array}$ & $30(37.50 \%)$ \\
$2.5-5.0$ years & $33(41.25 \%)$ \\
$>5$ years & $17(21.25 \%)$ \\
\hline HbA1C & \\
$<7 \%$ & $22(27.50 \%)$ \\
$7-8 \%$ & $27(33.75 \%)$ \\
$>8 \%$ & $31(38.75 \%)$ \\
\hline
\end{tabular}

HbA1C: glycosylated hemoglobin.

$35.55 \pm 5.16 \%$ in the control group $(P<0.02)$. The mean polymegathism of the left eye was $36.45 \pm 5.47 \%$ in the diabetic group versus $34.45 \pm 3.03 \%$ in control group $(P<0.03)$.

As shown in Tables 4 and 5 , the only factor affecting corneal endothelium morphology in children with type 1 diabetes was the duration of diabetes. We determined the odds ratio (95\% confidence intervals) and did not find any correlation between ECD, CCT, pleomorphism, polymegathism, and the following variables: the age of the patients, gender, $\mathrm{HbAlC}$ level, $\mathrm{BMI}$, hemoglobin level, and presence of diabetic retinopathy.

As shown in Table 4, there was a positive correlation between right CCT, left CCT, and duration of diabetes in years (odds ratio $(95 \%$ confidence intervals $)=6.53(2.19: 10.88)$ and 5.22 (1.20: 9.25), $P$ value $=0.004$ and 0.01 , resp.). Moreover, as shown in Figures 1 and 2, there was a negative correlation between the mean right ECD, left ECD, and the duration of diabetes in years $(r=-0.51, P=0.003$, and $r=-0.52$, $P=0.003$, resp.).

Furthermore, as shown in Table 5, there was a negative correlation between right corneal pleomorphism, left

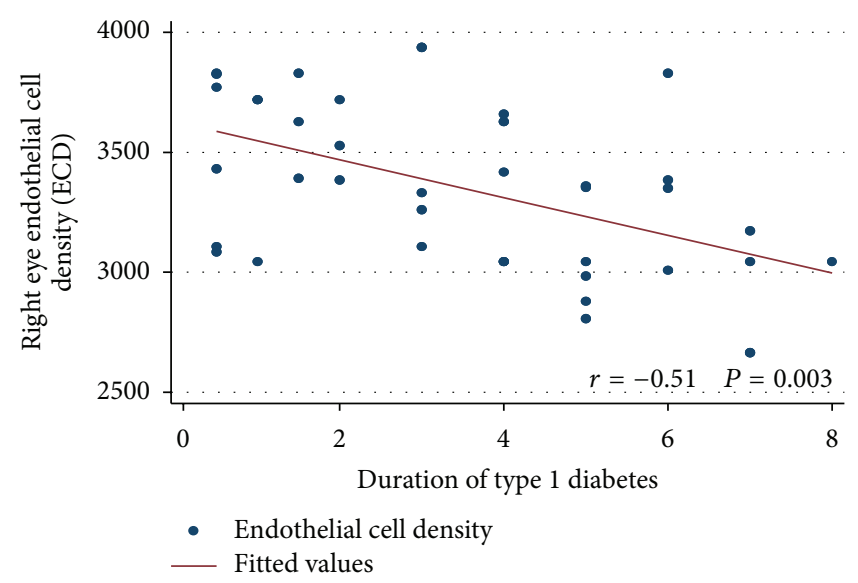

FIGURE 1: Correlation between the right endothelial cell density (ECD) and duration of type 1 diabetes in years.

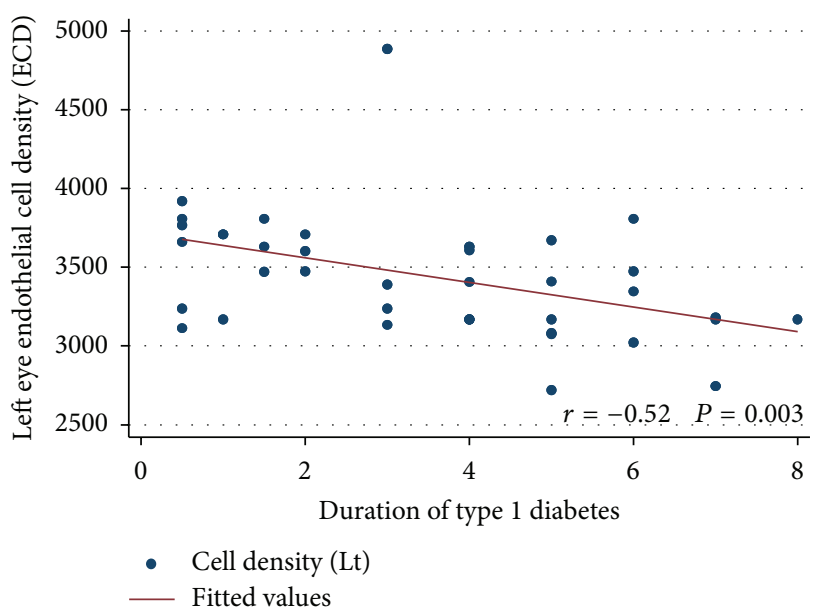

FIGURE 2: Correlation between the left endothelial cell density (ECD) and duration of type 1 diabetes in years. 
TABLE 3: Comparison between type 1 diabetes patients and healthy controls as regards corneal endothelial morphology.

\begin{tabular}{|c|c|c|c|}
\hline Patient characteristics & Type 1 diabetes & Healthy controls & $P$ value \\
\hline \multicolumn{4}{|c|}{ Right central corneal thickness (microns) } \\
\hline Mean (SD) & $537 \pm 33.41$ & $504.7 \pm 23.99$ & $<0.0001$ \\
\hline \multicolumn{4}{|c|}{ Right endothelial cell density (cells $/ \mathrm{mm}^{2}$ ) } \\
\hline Mean (SD) & $3149.84 \pm 343.75$ & $3308.78 \pm 99.33$ & 0.005 \\
\hline \multicolumn{4}{|l|}{ Right pleomorphism \% } \\
\hline Mean (SD) & $48.73 \pm 5.43$ & $56.46 \pm 9.64$ & $<0.0001$ \\
\hline \multicolumn{4}{|l|}{ Right polymegathism \% } \\
\hline Mean (SD) & $37.96 \pm 5.61$ & $35.55 \pm 5.16$ & 0.02 \\
\hline \multicolumn{4}{|c|}{ Left central corneal thickness (microns) } \\
\hline Mean (SD) & $539.91 \pm 30.49$ & $501.63 \pm 15.77$ & $<0.0001$ \\
\hline \multicolumn{4}{|c|}{ Left endothelial cell density $\left(\right.$ cells $/ \mathrm{mm}^{2}$ ) } \\
\hline Mean (SD) & $3142.13 \pm 416.74$ & $3315.25 \pm 100.16$ & 0.01 \\
\hline \multicolumn{4}{|l|}{ Left pleomorphism \% } \\
\hline Mean (SD) & $49.67 \pm 6.87$ & $55.14 \pm 10.27$ & 0.003 \\
\hline \multicolumn{4}{|l|}{ Left polymegathism } \\
\hline Mean (SD) & $36.45 \pm 5.47$ & $34.45 \pm 3.03$ & 0.03 \\
\hline
\end{tabular}

Pleomorphism: percentage of normal hexagonal cells; polymegathism: percentage of abnormal corneal cell size.

corneal pleomorphism, and the duration of diabetes in years (odds ratio (95\% confidence intervals) $=-1.11(-2.32: 0.19)$ and $-0.66(-1.8:-0.41), P$ value $=0.04$ and 0.02 , resp.). Moreover, there was a positive correlation between the right corneal polymegathism, left corneal polymegathism, and the duration of diabetes in years (odds ratio (95\% confidence intervals $)=0.61(0.23: 1.81)$ and $5.22(1.20: 9.25), P$ value $=$ 0.04 and 0.01 , resp.).

\section{Discussion}

With the progress of the techniques and instrumentation used in the evaluation of the corneal endothelial cells from the contact to noncontact specular microscopy, we were encouraged to evaluate the corneal endothelial cell morphology in children with certain eye and systemic diseases compared to normal children. Of course, diabetes mellitus is considered one of the most systemic diseases affecting the eye in general, and, in particular, we opened a window in this study to see the effect of type 1 diabetes on the corneal endothelial cell count and morphology in children. We found that the central cornea of type 1 diabetes is generally thicker than that of normal persons and had lower corneal endothelial cell density, lower hexagonality, and higher CV of cell size compared to nondiabetic children.

Several studies have been done to evaluate the corneal endothelial cells in diabetic adults [16-20]. Most of these studies agreed that diabetic corneas tend to be thicker and had more polymegathism and less pleomorphism, and they correlated these changes to the duration of the diabetes and/or to the status of the metabolic control. However, there have been very limited studies concerning the changes that occur in corneal endothelium of diabetic children, and the cause for the scant studies is not clear but may be explained by the fact that the noncontact specular microscope used in these measurements has only recently become available.

In our study we evaluated the changes that may occur in the corneal endothelium of diabetic children and compared these changes with the endothelium of nondiabetic children. We tried to find the risk factors that may contribute to these changes. For this reason, we evaluated four parameters of the corneal endothelium including the CCT, ECD, pleomorphism, and polymegathism. We have established that the mean CCT is higher in children with diabetes than in normal children and mean ECD is lower.

Similar results were obtained by Urban et al. [14] who examined 123 eyes of type 1 diabetic children and 124 eyes of nondiabetic children. The mean age of diabetic children was $15.34 \pm 3.06$ years versus $14.58 \pm 2.01$ years in the control group. The mean duration of diabetes was $8.02 \pm 3.9$ years. They found a reduction of the ECD by $18 \%$ compared to the control group. They also found that the mean CCT was $550 \pm$ 30 microns in the diabetic group versus $530 \pm 33$ microns in the control group.

In a study done by Tiutiuca [15] in which the CCT was measured for 100 children with type 1 diabetes (study group) and 100 healthy children (control group), the average CCT in diabetic children was $541 \pm 30$ microns for the right eye and $538 \pm 32$ microns for the left eye; in the control group it was $528 \pm 33$ microns for the right eye and $526 \pm 30$ microns for the left eye. He concluded that diabetic children have a significantly increased CCT when compared with nondiabetic children. The same results were obtained in another study by Urban et al. [21] who also evaluated corneal thickness in diabetic and nondiabetic children. They found a significant increase in the CCT in diabetic children when compared to nondiabetic controls. 
TABLE 4: Factors affecting corneal endothelial morphology of type 1 diabetes as regards central corneal thickness and endothelial cell density.

\begin{tabular}{|c|c|c|}
\hline & $\begin{array}{c}\text { Odds ratio } \\
(95 \% \text { confidence intervals })\end{array}$ & $P$ value \\
\hline \multicolumn{3}{|c|}{ Factors affecting right central corneal thickness } \\
\hline Age & $-3.68(-7.84: 0.47)$ & 0.08 \\
\hline Male versus female & $5.51(-9.90: 20.93)$ & 0.47 \\
\hline Duration of type 1 diabetes/years & $6.53(2.19: 10.88)$ & 0.004 \\
\hline BMI & $-0.52(-3.66: 2.63)$ & 0.74 \\
\hline Hemoglobin & $6.30(-5.14: 17.75)$ & 0.28 \\
\hline $\mathrm{HbA1C}$ & $2.13(-2.09: 6.35)$ & 0.32 \\
\hline \multicolumn{3}{|c|}{ Factors affecting left central corneal thickness } \\
\hline Age & $-3.15(-6.99: 0.69)$ & 0.10 \\
\hline Male versus female & $3.86(-10.41: 18.13)$ & 0.59 \\
\hline Duration of type 1 diabetes/years & $5.22(1.20: 9.25)$ & 0.01 \\
\hline BMI & $-0.63(-3.54: 2.28)$ & 0.67 \\
\hline Hemoglobin & $2.96(-7.64: 13.56)$ & 0.58 \\
\hline $\mathrm{HbAlC}$ & $0.03(-3.87: 3.94)$ & 0.98 \\
\hline \multicolumn{3}{|c|}{ Factors affecting right endothelial cell density } \\
\hline Age & $0.18(-0.49: 0.79)$ & 0.61 \\
\hline Male versus female & $-4.79(-7.28: 2.31)$ & 0.35 \\
\hline Duration of type 1 diabetes/years & $-35.93(-67.38:-4.48)$ & 0.03 \\
\hline BMI & $-6.69(-29.41: 16.02)$ & 0.56 \\
\hline Hemoglobin & $54.34(-28.46: 137.13)$ & 0.20 \\
\hline $\mathrm{HbAlC}$ & $4.11(-6.60: 7.62)$ & 0.31 \\
\hline \multicolumn{3}{|c|}{ Factors affecting left endothelial cell density } \\
\hline Age & $0.16(-0.47: 0.80)$ & 0.62 \\
\hline Male versus female & $-4.35(-6.70: 2.00)$ & 0.34 \\
\hline Duration of type 1 diabetes/years & $-32.93(-65.38:-6.48)$ & 0.03 \\
\hline BMI & $0.03(-0.45: 0.51)$ & 0.90 \\
\hline Hemoglobin & $-1.21(-2.96: 0.53)$ & 0.17 \\
\hline $\mathrm{HbA1C}$ & $-0.04(-0.68: 0.61)$ & 0.91 \\
\hline
\end{tabular}

BMI: body mass index; HbAlC: glycosylated hemoglobin.

Furthermore, a study was done by Módis Jr. et al. [22] who compared the effect of type 1 and type 2 diabetes on the corneal endothelial cell morphology. There was a statistically significant decreased ECD in type 1 diabetes in comparison with healthy subjects, but in type 2 diabetes no significant difference was found in the evaluated values. The mean age of type 1 diabetes in Módis Jr. et al.s study was $40.97 \pm 15.46$ compared to $8.22 \pm 3.11$ in our study. Also, Roszkowska et al. [8], after examining 75 adults with type 1 and type 2 diabetes, noted that the ECD decreased by $5 \%$ in type 2 diabetes and by $11 \%$ in type 1 diabetes when compared with healthy persons.

In a relatively old study done by Schultz et al. [23], a significantly higher rate of cell loss in type 1 diabetes was detected, resulting in a significant decrease in ECD in the fourth and fifth decades. On the other hand, several studies have evaluated the effect of type 2 diabetes on corneal endothelium $[18,20,24-26]$. Most of these studies agreed that the ECD is reduced and the cornea is thicker in type 2 diabetes.
Different results were obtained by Larsson et al. [13] who examined 49 patients with type 1 diabetes and 60 patients with type 2 diabetes. They concluded that neither type 1 diabetes patients nor type 2 diabetes patients differed from their controls in ECD but type 1 diabetes patients had thicker corneas. Furthermore, Furuse et al. [27] did not demonstrate significant changes in mean ECD in diabetic subjects, but they only examined patients with type 2 diabetes.

In order to determine the systemic and local risk factors affecting the corneal endothelial morphology in children with type 1 diabetes, we determined the odds ratio (95\% confidence intervals) and we did not find any correlation between ECD and CCT with the following variables: the age of the patients, gender, $\mathrm{HbAlC}$ level, BMI, and hemoglobin level. In this study the only factor affecting corneal endothelium morphology in type 1 diabetes patients was the duration of diabetes. The same results were obtained by Urban et al. [14] who demonstrated a significant correlation between ECD and the duration of diabetes in children. Also, Busted et al. [28] 
TABLE 5: Factors affecting corneal endothelial morphology of type 1 diabetes as regards corneal pleomorphism and polymegathism.

\begin{tabular}{|c|c|c|}
\hline & $\begin{array}{c}\text { Odds ratio } \\
\text { (95\% confidence intervals) }\end{array}$ & $P$ value \\
\hline \multicolumn{3}{|c|}{ Factor affecting right corneal pleomorphism } \\
\hline Age & $0.59(-0.57: 1.74)$ & 0.31 \\
\hline Male versus female & $5.33(-1.06: 9.61)$ & 0.15 \\
\hline Duration of type 1 diabetes/years & $-1.11(-2.32: 0.19)$ & 0.04 \\
\hline BMI & $-0.64(-0.151: 0.23)$ & 0.15 \\
\hline Hemoglobin & $-0.11(-3.29: 3.06)$ & 0.94 \\
\hline $\mathrm{HbA1C}$ & $0.26(-0.91: 1.43)$ & 0.66 \\
\hline \multicolumn{3}{|c|}{ Factor affecting left corneal pleomorphism } \\
\hline Age & $-1.24(-2.36: 0.12)$ & 0.30 \\
\hline Male versus female & $7.40(-3.22: 11.56)$ & 0.18 \\
\hline Duration of type 1 diabetes/years & $-0.66(-1.8:-0.41)$ & 0.02 \\
\hline BMI & $-0.22(-0.62: 1.07)$ & 0.60 \\
\hline Hemoglobin & $2.45(-0.64: 5.54)$ & 0.12 \\
\hline $\mathrm{HbAlC}$ & $-0.27(-1.41: 0.87)$ & 0.65 \\
\hline \multicolumn{3}{|c|}{ Factor affecting right corneal polymegathism } \\
\hline Age & $-0.28(-0.91: 0.35)$ & 0.38 \\
\hline Male versus female & $-4.02(-6.36: 1.68)$ & 0.14 \\
\hline Duration of type 1 diabetes/years & $0.61(0.23: 1.81)$ & 0.04 \\
\hline BMI & $0.43(-0.40: 0.91)$ & 0.11 \\
\hline Hemoglobin & $0.51(-1.23: 2.24)$ & 0.56 \\
\hline $\mathrm{HbAlC}$ & $-0.36(-0.99: 0.28)$ & 0.27 \\
\hline \multicolumn{3}{|c|}{ Factor affecting left corneal polymegathism } \\
\hline Age & $0.16(-0.47: 0.79)$ & 0.62 \\
\hline Male versus female & $-4.35(-6.70: 2.01)$ & 0.45 \\
\hline Duration of type 1 diabetes/years & $5.22(1.20: 9.25)$ & 0.01 \\
\hline BMI & $0.03(0.45: 0.51)$ & 0.90 \\
\hline Hemoglobin & $-1.21(-2.96: 0.53)$ & 0.17 \\
\hline $\mathrm{HbA1C}$ & $-0.04(-0.68: 0.61)$ & 0.91 \\
\hline
\end{tabular}

BMI: body mass index; HbAlC: glycosylated hemoglobin.

found a correlation between the lower ECD and the higher CCT in type 1 diabetes patients with the duration of the disease, but the decrease per year was of the same magnitude as the normal age dependence.

Furthermore, Calvo-Maroto et al. [18] found in a study on adult patients with type 2 diabetes significant alteration in corneal structure and function in the long term diabetes of more than 10 years with poor glycemic control. Moreover, Lee et al. [29] found a correlation between the diabetes duration with only the CCT but not with the ECD. There were different studies that did not find any correlated risk factors with the endothelial cell changes in diabetic patients, but these studies were conducted in type 2 diabetes [24-26, 30, 31].

In this study, there were no cases with diabetic retinopathy. However, Siribunkum et al. [32] in adult diabetic patients found a correlation between the severity of diabetic retinopathy and the reduction in ECD, while the CCT was correlated only with the duration of the disease. They also found that the corneal changes were not correlated with glycemic control.
Moreover, Módis Jr. et al. [22] found that HbA1C is inversely correlated with ECD in type 1 diabetes, while in type 2 diabetes no changes occurred. Ziadi et al. [33] did not detect any relation between the level of $\mathrm{HbA1C}$ and the condition of the corneal endothelium.

Furthermore, we have established a significant increase in polymegathism and decrease in pleomorphism in children with type 1 diabetes. Also, we found that the only risk correlated with the changes in the polymegathism and pleomorphism is the duration of the disease. The same results were obtained by Módis Jr. et al. [22]. Moreover, Lee et al. [29] found that diabetic subjects had less hexagonality and a more irregular cell size of the corneal endothelium than did the controls. Like our study, they correlated the corneal morphological abnormalities, especially the coefficient of variation in cell size, to the duration of diabetes.

Inoue et al. [30] investigated the corneal endothelial structure in 99 patients with type 2 diabetes and in 97 nondiabetic patients. They found an increase in the polymegathism 
in diabetic patients. However, the pleomorphism in diabetic patients was not significantly different from that in nondiabetic patients. Siribunkum et al. [32] concluded in their study that the diabetic corneas had more polymegathism and less pleomorphism, though this was not statistically significant. The duration of diabetes was correlated significantly with these corneal changes.

Also Larsson et al. [13] noticed significant variability in endothelial cell size and a significant decrease in endothelial cell hexagonality in type 1 diabetes patients when compared to their controls. They concluded that the corneas of patients with type 1 diabetes exhibit abnormalities in endothelial cell morphologic characteristics. The changes resemble those that occur with aging in normal subjects.

Matsuda et al. [31] found that, in type 2 diabetes, when compared to age-matched nondiabetic controls, all diabetic groups demonstrated significant increases in cell size and shape variability. Unlike our study, none of the endothelial morphologic parameters were found to correlate with the duration of diabetes or glycemic control. On the other hand, their study was conducted on patients with type 2 diabetes.

\section{Conclusion}

The conclusion of this study is that diabetic children have thicker corneas, lower ECD, an increase in cell size variability $(\mathrm{CV})$, and a decrease in the hexagonal cells. The duration of diabetes is the factor that affects all of these changes. To what extent these changes affect visional function on long term needs to be investigated in further studies.

\section{Competing Interests}

The authors declare that there are no competing interests regarding the publication of this paper.

\section{Acknowledgments}

The authors thank http://proof-reading-services.com/ for linguistic editing.

\section{References}

[1] M. A. E.-M. El-Ziny, N. A.-B. Salem, A. K. El-Hawary, N. M. Chalaby, and A. A.-E. Elsharkawy, "Epidemiology of childhood type 1 diabetes mellitus in Nile Delta, northern Egypt-a retrospective study," Journal of Clinical Research in Pediatric Endocrinology, vol. 6, no. 1, pp. 9-15, 2014.

[2] R. Misra, C. Fitch, D. Roberts, and D. Wright, "Communitybased diabetes screening and risk assessment in rural west virginia," Journal of Diabetes Research, vol. 2016, Article ID 2456518, 9 pages, 2016.

[3] A.-K. Imkampe and M. C. Gulliford, "Trends in Type 1 diabetes incidence in the UK in 0- to 14-year-olds and in 15- to 34-yearolds, 1991-2008," Diabetic Medicine, vol. 28, no. 7, pp. 811-814, 2011.

[4] M. M. Geloneck, B. J. Forbes, J. Shaffer, G.-S. Ying, and G. Binenbaum, "Ocular complications in children with diabetes mellitus," Ophthalmology, vol. 122, no. 12, pp. 2457-2464, 2015.
[5] W. M. Bourne, L. I. L. Nelson, and D. O. Hodge, "Central corneal endothelial cell changes over a ten-year period," Investigative Ophthalmology \& Visual Science, vol. 38, no. 3, pp. 779-782, 1997.

[6] B. Urban, A. Bakunowicz-Łazarczyk, and M. Kretowska, "Corneal endothelium in children and adolescents with myopia," Klinika Oczna, vol. 104, no. 5-6, pp. 381-383, 2002.

[7] S.-W. Chang, F.-R. Hu, and L. L.-K. Lin, "Effects of contact lenses on corneal endothelium-a morphological and functional study," Ophthalmologica, vol. 215, no. 3, pp. 197-203, 2001.

[8] A. M. Roszkowska, C. G. Tringali, P. Colosi, C. A. Squeri, and G. Ferreri, "Corneal endothelium evaluation in type I and type II diabetes mellitus," Ophthalmologica, vol. 213, no. 4, pp. 258-261, 1999.

[9] N. C. Joyce and D. L. Harris, "Decreasing expression of the G1phase inhibitors, p21Cipl and p16ink4a, promotes division of corneal endothelial cells from older donors," Molecular Vision, vol. 16, pp. 897-906, 2010.

[10] T. N. Didenko, G. P. Smoliakova, E. L. Sorokin, and V. V. Egorov, "Clinical and pathogenetic features of neurotrophic corneal disorders in diabetes," Vestnik Oftalmologii, vol. 115, no. 6, pp. 7-11, 1999.

[11] A. Kabosova, A. A. Kramerov, A. M. Aoki, G. Murphy, J. D. Zieske, and A. V. Ljubimov, "Human diabetic corneas preserve wound healing, basement membrane, integrin and MMP-10 differences from normal corneas in organ culture," Experimental Eye Research, vol. 77, no. 2, pp. 211-217, 2003.

[12] G. M. Keoleian, J. M. Pach, D. O. Hodge, S. D. Trocme, and W. M. Bourne, "Structural and functional studies of the corneal endothelium in diabetes mellitus," The American Journal of Ophthalmology, vol. 113, no. 1, pp. 64-70, 1992.

[13] L.-I. Larsson, W. M. Bourne, J. M. Pach, and R. F. Brubaker, "Structure and function of the corneal endothelium in diabetes mellitus type I and type II," Archives of Ophthalmology, vol. 114, no. 1, pp. 9-14, 1996.

[14] B. Urban, D. Raczyńska, A. Bakunowicz-Lazarczyk, K. Raczyńska, and M. Krętowska, "Evaluation of corneal endothelium in children and adolescents with type 1 diabetes mellitus," Mediators of Inflammation, vol. 2013, Article ID 913754, 6 pages, 2013.

[15] C. Tiutiuca, "Assessment of central corneal thickness in children with diabetus mellitus type I," Oftalmologia, vol. 57, no. 1, pp. 26$32,2013$.

[16] H. S. Leem, K. J. Lee, and K. C. Shin, "Central corneal thickness and corneal endothelial cell changes caused by contact lens use in diabetic patients," Yonsei Medical Journal, vol. 52, no. 2, pp. 322-325, 2011.

[17] W. Leelawongtawun, W. Suphachearaphan, K. Kampitak, and R. Leelawongtawun, "A comparative study of corneal endothelial structure between diabetes and non-diabetes," Journal of the Medical Association of Thailand, vol. 98, no. 5, pp. 484-488, 2015.

[18] A. M. Calvo-Maroto, A. Cerviño, R. J. Perez-Cambrodí, S. García-Lázaro, and J. A. Sanchis-Gimeno, "Quantitative corneal anatomy: evaluation of the effect of diabetes duration on the endothelial cell density and corneal thickness," Ophthalmic and Physiological Optics, vol. 35, no. 3, pp. 293-298, 2015.

[19] A. Storr-Paulsen, A. Singh, H. Jeppesen, J. C. Norregaard, and J. Thulesen, "Corneal endothelial morphology and central thickness in patients with type II diabetes mellitus," Acta Ophthalmologica, vol. 92, no. 2, pp. 158-160, 2014. 
[20] R. R. Sudhir, R. Raman, and T. Sharma, "Changes in the corneal endothelial cell density and morphology in patients with type 2 diabetes mellitus: a population-based study, Sankara Nethralaya diabetic retinopathy and molecular genetics study (SN-DREAMS, Report 23)," Cornea, vol. 31, no. 10, pp. 1119-1122, 2012.

[21] B. Urban, J. Peczyńska, B. Głowińska-Olszewska, M. Urban, A. Bakunowicz-Łazarczyk, and M. Krętowska, "Evaluation of central corneal thickness in children and adolescents with type I diabetes mellitus," Klinika Oczna, vol. 109, no. 10-12, pp. 418420, 2007.

[22] L. Módis Jr., E. Szalai, K. Kertész, Á. Kemény-Beke, B. Kettesy, and A. Berta, "Evaluation of the corneal endothelium in patients with diabetes mellitus type I and II," Histology and Histopathology, vol. 25, no. 12, pp. 1531-1537, 2010.

[23] R. O. Schultz, M. Matsuda, R. W. Yee, H. F. Edelhauser, and K. J. Schultz, "Corneal endothelial changes in type I and type II diabetes mellitus," American Journal of Ophthalmology, vol. 98, no. 4, pp. 401-410, 1984.

[24] S. Briggs, U. L. Osuagwu, and E. M. AlHarthi, "Manifestations of type 2 diabetes in corneal endothelial cell density, corneal thickness and intraocular pressure," Journal of Biomedical Research, vol. 30, no. 1, pp. 46-51, 2016.

[25] S. Galgauskas, G. Laurinavičiūtè, D. Norvydaitè, S. Stech, and R. Ašoklis, "Changes in choroidal thickness and corneal parameters in diabetic eyes," European Journal of Ophthalmology, vol. 26, no. 2, pp. 163-167, 2015.

[26] M. M. Choo, K. Prakash, A. Samsudin, and A. J. Kadir, "Corneal changes in type ii diabetes mellitus in malaysia," International Journal of Ophthalmology, vol. 3, no. 3, pp. 234-236, 2010.

[27] N. Furuse, S. Hayasaka, Y. Yamamoto, and T. Setogawa, "Corneal endothelial changes after posterior chamber intraocular lens implantation in patients with or without diabetes mellitus," British Journal of Ophthalmology, vol. 74, no. 5, pp. 258-260, 1990.

[28] N. Busted, T. Olsen, and O. Schmitz, "Clinical observations on the corneal thickness and the corneal endothelium in diabetes mellitus," British Journal of Ophthalmology, vol. 65, no. 10, pp. 687-690, 1981.

[29] J. S. Lee, B. S. Oum, H. Y. Choi, J. E. Lee, and B. M. Cho, "Differences in corneal thickness and corneal endothelium related to duration in diabetes," Eye, vol. 20, no. 3, pp. 315-318, 2006.

[30] K. Inoue, S. Kato, Y. Inoue, S. Amano, and T. Oshika, "The corneal endothelium and thickness in type II diabetes mellitus," Japanese Journal of Ophthalmology, vol. 46, no. 1, pp. 65-69, 2002.

[31] M. Matsuda, N. Ohguro, I. Ishimoto, and M. Fukuda, "Relationship of corneal endothelial morphology to diabetic retinopathy, duration of diabetes and glycemic control," Japanese Journal of Ophthalmology, vol. 34, no. 1, pp. 53-56, 1990.

[32] J. Siribunkum, P. Kosrirukvongs, and A. Singalavanija, "Corneal abnormalities in diabetes," Journal of the Medical Association of Thailand, vol. 84, no. 8, pp. 1075-1083, 2001.

[33] M. Z. Ziadi, P. Moiroux, P. D. Athis, A. Bron, J. M. Brun, and C. Creuzot-Garcher, "Assessment of induced corneal hypoxia in diabetic patients," Cornea, vol. 21, no. 5, pp. 453-457, 2002. 


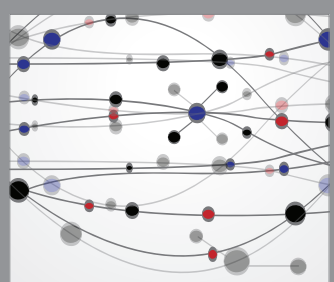

The Scientific World Journal
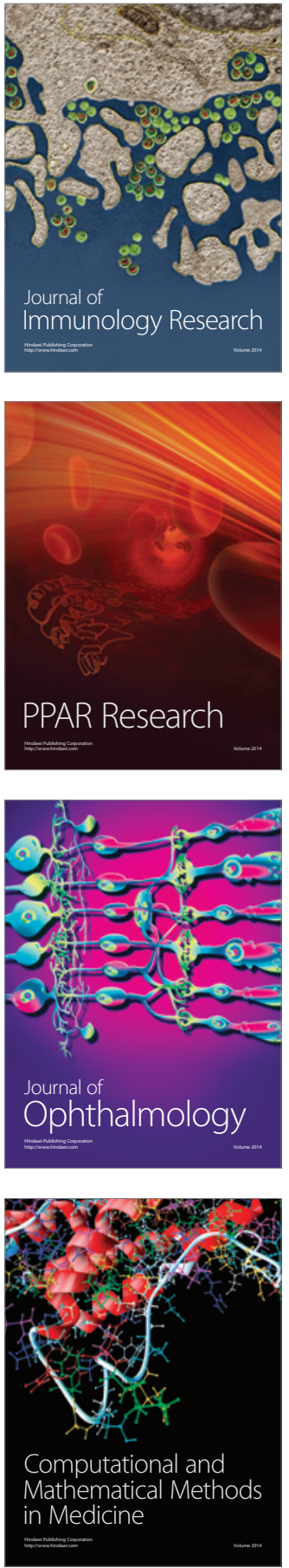

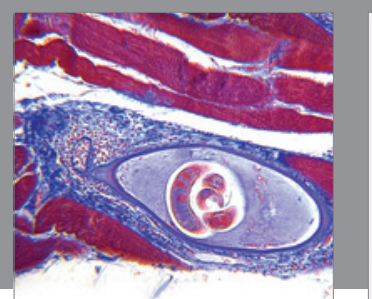

Gastroenterology Research and Practice

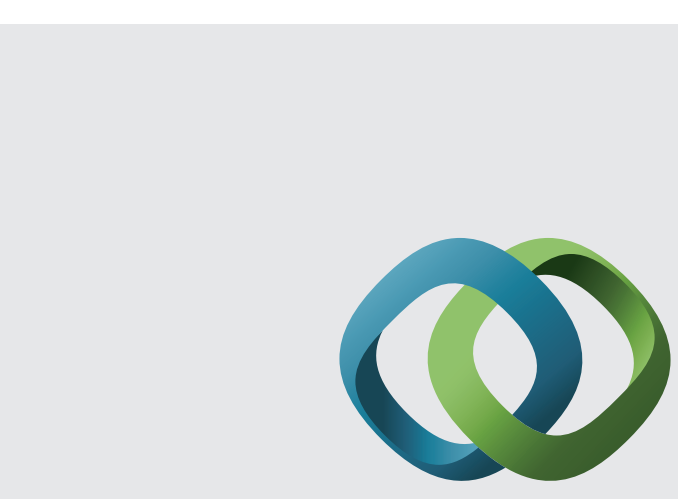

\section{Hindawi}

Submit your manuscripts at

http://www.hindawi.com
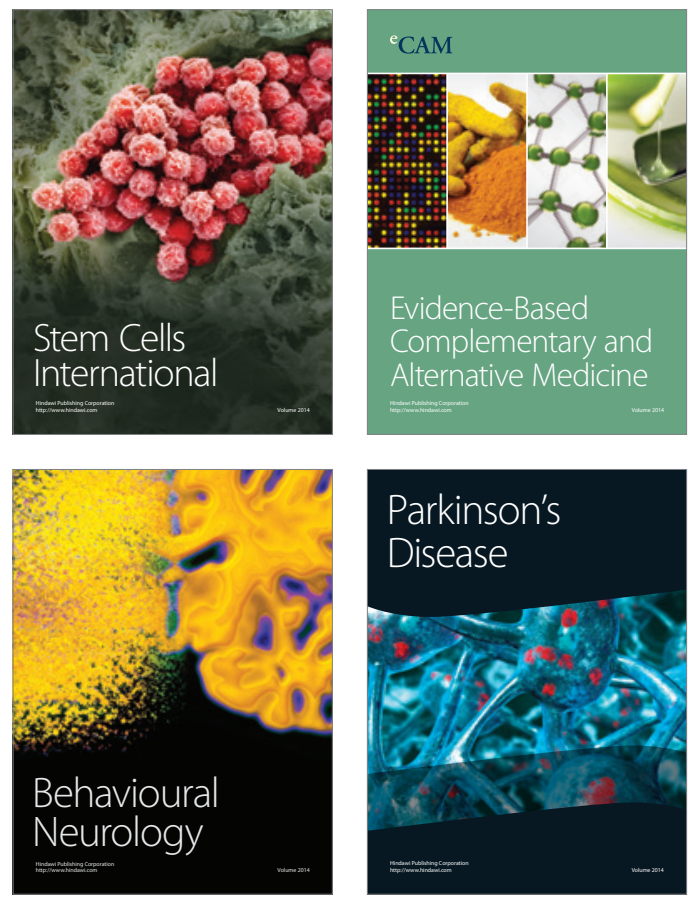
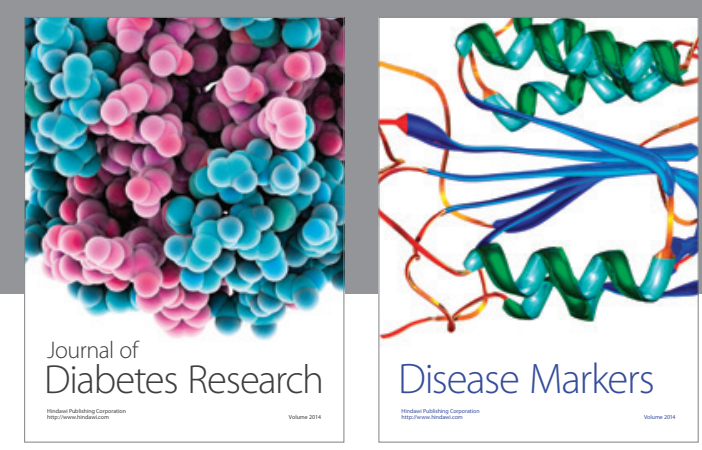

Disease Markers
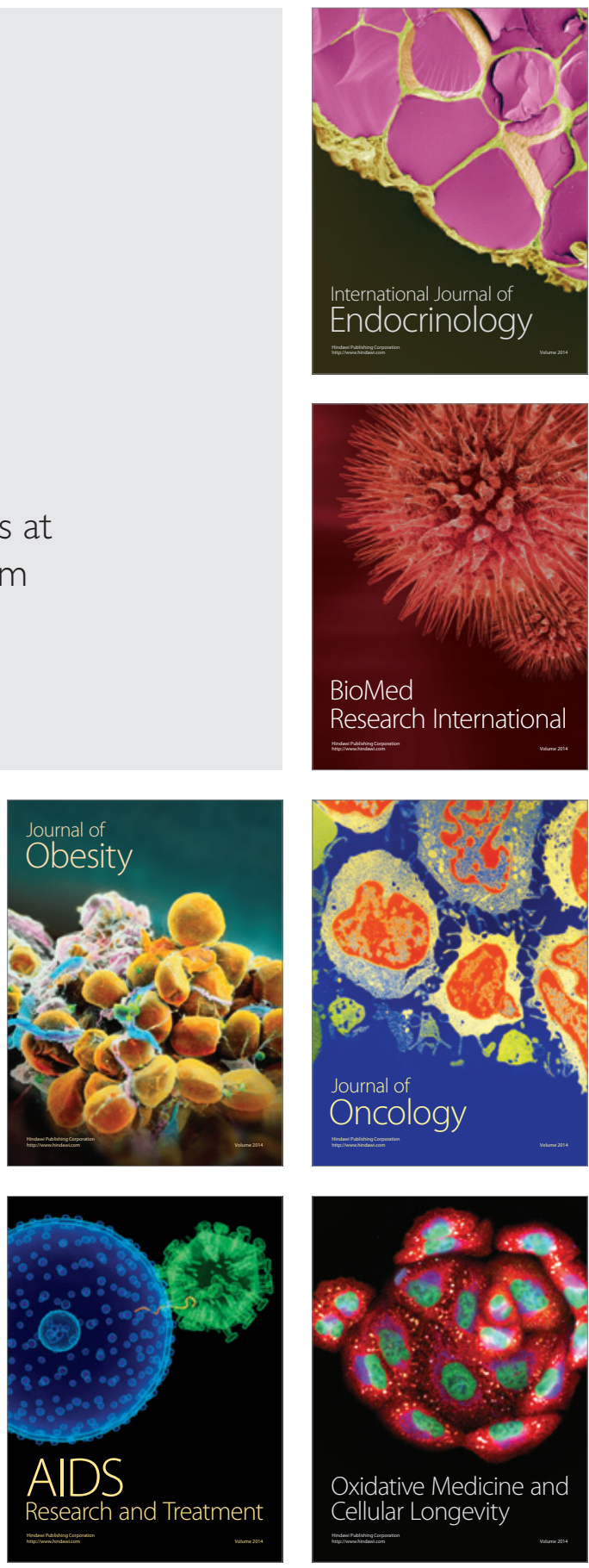